\title{
A RARE CASE OF DIFFUSE SUBARACHNOID AND SUBDURAL HEMORRHAGE DUE TO CEREBRAL SINOVENOUS AND CORTICAL VEIN THROMBOSIS IN AN INFANT WITH PURULENT OTITIS MEDIA
}

\section{SVIRKOS, E CHOCHLIOUROU, E VOLAKLI, E KARAKEKE, A GOGOVITOU, M SDOUGKA P.I.C.U., "HIPPOKRATEION" GENERAL HOSPITAL OF THESSALONIKI, GREECE}

A 1.5 year infant has been hospitalized in our P.I.C.U. due to diffuse subdural (SDH) and subarachnoid hemorrhage (SAH) associated with cerebral sinovenous thrombosis (CSVT)

The previous days he had rhinitis, cough and fever up to $39^{\circ} \mathrm{C}$. Acute otitis media was diagnosed and an antibiotic was administered. The infant was not vaccinated at all

He presented sudden loss of consciousness and eyeball upward deviation without headache, vomiting or breathing disorders. Opisthotonus was described. His pupils remained isocoric with equal light reflex

He was intubated because of persistent low GCS $(<\mathbf{8})$ despite anticonvulsant administration

An MD/CT imaging was performed and SDH and $\mathrm{SAH}$ with partial thrombosis of the right transverse and sigmoid sinuses with ipsilateral CVT were detected

The findings were confirmed the next day by MRI MRA - MRV imaging. Normal ventricular system and no cerebral edema were detected. Sinusitis was also found
LMWH was administered. During his stay seizures equivalents occurred and his treatment was adequately modified

$\square \mathrm{C} / \mathrm{T}$ imaging was repeated twice and the findings were improved

$\square$ The infant was extubated and transferred to a pediatric clinic with neurologic disability of some degree

Conclusions: CVT is an uncommon site of involvement in (CSVT). Involvement of cortical veins in CSVT is associated with an increased risk of seizures at presentation, infarction and adverse outcome in children
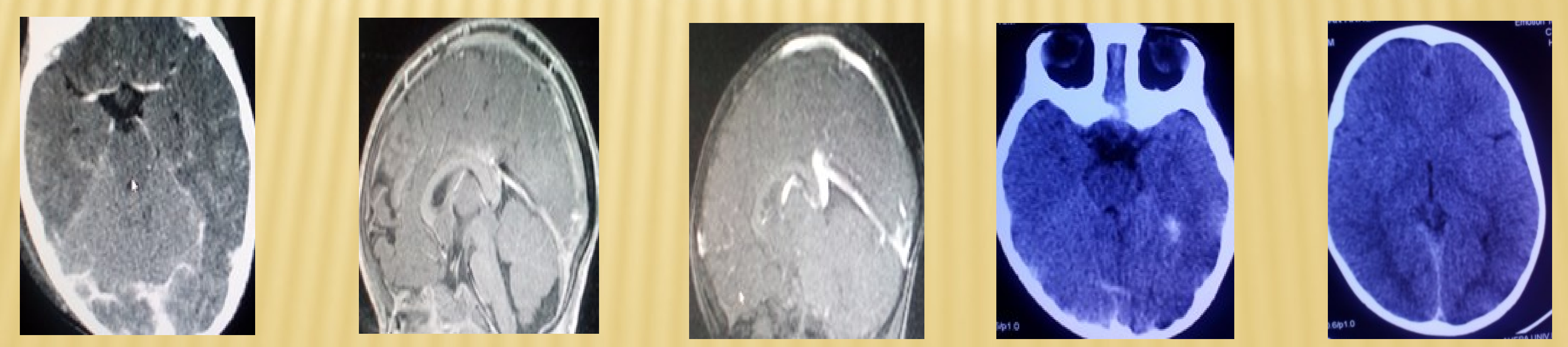